DOI 10.37882/2223-2982.2020.10-2.17

\title{
АРАБСКИЕ ЗАИМСТВОВАНИЯ В СОВРЕМЕННОМ РУССКОМ ЯЗЫКЕ: ВЗАИМОДЕЙСТВИЕ «НА ПЕРЕСЕЧЕНИИ КУЛЬТУР»
}

\section{ARABIC BORROWINGS IN MODERN RUSSIAN: INTERACTION "AT THE INTERSECTION OF CULTURES" \\ E. Senko \\ Z. Garieva}

Summary: Arabic lexemes that are actively translated into the Russian language system and demonstrate the «intersection» of the Russian national mentality with foreign linguistic and cultural values in the process of intercultural communication are described as the subject of the research. The purpose of the article is to study Arabic occurrences not only as constituents of a particular language, but as a linguistic phenomenon that «passes» through different cultures. For the first time, different vectors of the linguistic and cultural history of Arabic words functioning in the Russian language system are noted. As a result, it is established that interlanguage contact causes the actualization of those components of the word semantics that require knowledge of additional background associations. The contrastive-semantic analysis States that while preserving the denotative meaning, arabisms undergo significative transformations that depend on the conceptual world of communicants.

Keywords: linguistic contact, borrowing, Arabism, actualization, crosscultural, contrastive-semantic.
Сенько Елена Викторовна

Д.филол.н., профессор, ФГБОУ ВО «Северо-Осетинский государственный университет имени Коста Левановича Хетагурова» (2. Владикавказ) senkoelena@yandex.ru

Гариева Зарема Давидовна

ФГБОУ ВО «Северо-Осетинский государственный университет имени Коста Левановича Хетагурова»

(2. Владикавказ)

kazieva96@bk.ru

Аннотация: В качестве предмета исследования описаны арабские лексемы, активно транслируемые в русскую языковую систему и демонстрирующие «пересечение» русского национального менталитета с чужими лингвокультурными ценностями в процессе межкультурной коммуникации. Цель cтатьи - изучить арабские вхождения не только как конституенты того или иного языка, а как «проходящее» через разные культуры лингвистическое явление. Впервые отмечены разные векторы лингвокультурной истории арабских слов, функционирующих в русской языковой системе. В результате установлено, что межъязыковое контактирование обусловливает актуализацию тех компонентов семантики слова, которые требуют знания дополнительных фоновых ассоциаций. Контрастивно-семантический анализ констатирует, что при сохранении денотативного значения арабизмы претерпевают сигнификативные трансформации, зависящие от концептуального мира коммуникантов.

Ключевые слова: языковой контакт, заимствование, арабизм, актуализация, кросскультурный, контрастивно-семантический.

\section{Введение}

И звестно, что современный русский язык характеризуется достаточно низким уровнем лексической стабильности: русская языковая система интенсивно демонстрирует разнонаправленные векторы своего развития.

Один из основных механизмов языковой динамики-процесс заимствования, обусловленный активно протекающей в современном мире глобализацией, способствующей превращению мирового пространства в единую систему. В связи со сказанным процесс языкового контактирования, всегда привлекающий научное внимание, стал особенно актуальным как объект исследования многих отечественных и зарубежных лингвистов. Можно сказать, что указанная тема носит уже «хронический» характер. Однако трансляция единиц (как правило, лексических) из одного языка в другой исследуется обычно в экстралингвистической проекции. Между тем хорошо известно, что каждое слово другого языка отражает иные в сравнении с принимающим языком ценностные установки, связанные с индивидуальными свойствами той или иной ментальности. Значит, возникает некое противоречие между традиционным подходом к исследованию процесса заимствования и потребностями современной межкультурной коммуникации, обусловливающее необходимость исследовать не только системно-структурную сторону процесса заимствования, но и культурную «среду» существования языка.. Указанная проблема решается сформировавшимся относительно недавно кросскультурным методом лингвистического анализа. Актуальность предпринимаемого исследования обусловлена необходимостью выявления «пересечений» русского национального менталитета с чужими лингвокультурными ценностями в процессе межкультурной коммуникации. Научная новизна исследования заключается в том, что в статье впервые предпринимается попытка контрастивного семантического анализа актуальных арабских лексем, вошедших в русский литературный язык конца XX - начала XXI вв. Цель cтатьи - изучить арабские вхождения как реальный языковой факт, «проходящий» через неоднородные этнокультуры и обогащающиеся семами различного типа, 
в том числе инокультурными коннотациями. Наряду с общенаучными методами в статье применялся описательный метод, а также методы компонентного анализа и контрастивно-семантического, при помощи которых анализируемые лексические единицы семантически соотносились с их коррелятами в языке-источнике. Материалом исследования послужили данные толковых динамических словарей, словарей иностранных слов, а также современных СМИ, в том числе электронных. Кроме того были использованы примеры Национального корпуса русского языка.

\section{Результаты исследования}

Как уже было отмечено, одним из тенденциозных явлений XXI века является процесс глобализации, связанный прежде всего с расширением общеэтнического культурно-духовного пространства. Значительно влияя на культурные процессы, интеграция ведет к формированию единой мировой цивилизации. Однако при этом глобализация не отменяет культурного разнообразия, особенностей этно- и лингвокультурного развития тех или иных регионов. Сказанное обусловливает необходимость выходящего на новый уровень взаимопонимания участников межкультурного диалога и вместе с тем сохранения инокультурного своеобразия, что в свою очередь требует необходимость новых векторов исследования сложившейся экстралингвистической ситуации. Один из них - метод кросскультурного анализа, методика которого дает возможность репрезентировать особенности национальной культуры и ментальности на фоне межкультурной коммуникации.

В отечественном языкознании первые попытки кросскультурного исследования принадлежат специалистам по лингвострановедению, которые постулировали необходимость изучения языка в связи с культурой, повседневной жизнью и ценностными стереотипами его носителей. Впоследствии термин и соответствующий сигнификат транслировали в социологию, затем - в гендерную лингвистику, откуда он вошел и в другие лингвистические специализации.

Главную роль в лингвистической «стандартизации» кросскультурного анализа языковой системы сыграли исследования А. Вежбицкой, которая, «сравнивая слова, конструкции, тексты, являющиеся в различных языках как будто бы точными соответствиями, показывает, что прямые переводные эквиваленты могут скрывать существенные культурно обусловленные различия» [3, с. 166]. Таким образом. Проблема общения и взаимопонимания различных народов, носителей разных культур, привела к появлению названной выше лингвистической специализации, а именно кросскультурной лингвистики, название которой говорит о связи науки о языке с понятием кросскультурности. Соответствующее прилагательное трактуется следующим образом: кросскультурны «связанный с культурами разных народов и социальных групп, их взаимодействием (англ. Cross Culture «пересечение культур») [8].

Именно в этом направлении проводят исследования языка В.Н. Телия [17], В.В. Колесов [8], В.А. Маслова [12], М.К. Голованивская [4] и др. Последний из названных авторов работает в сфере лингвосопоставительной культурологии, которая, специализируясь на установлении в сравниваемых языках не столько общих признаков, сколько на констатации лингвокультурного своеобразия, более адекватно следует кросскультурной методологии.

Основным методом кросскультурного лингвистического исследования является контрастивно-сопоставительный анализ, суть которого - «выявление сходств и различий в семантике и функциях единицы одного языка в сравнении с ее соответствиями в другом языке. Главное при этом - выявление различий, сходства выявляются «автоматически» $[17$, с.68].

Культура этноса, как и любая другая сторона его жизни, отражается в понятийно-языковой картине мира. Последняя есть исторически сложившийся способ концептуализации действительности, зафиксированный в языке. В силу этого языковая картина мира отражает посредством языковых единиц заложенные в каждом этнокультурном сообществе национальные идеи, модели культурного восприятия и поведения.

Несомненна связь языковой картины с национальной; последняя «как единое целое может быть представлена в виде упорядоченной системы представлений национальной общности о мире, окружающей действительности, опосредованных языковыми составляющими» $[7$, с. 62].

В определение национальной картины мира входит понятие «менталитет», субъектом которого является не индивидуум, а социум. Несомненно, что ментальность есть его культурная часть. В связи со всем вышесказанным для кросскультурного метода в лингвистике несомненную актуальность представляет исследование современного процесса заимствования, который, как никакой другой языковой процесс, наглядно демонстрирует взаимодействие «на пересечении культур», осуществляемое через диалог разных этносов в процессе культурной глобализации, характеризующей современное общество и обеспечивающей возникновение новых форматов ценностей и норм поведения.

В ходе своего развития человечество породило множество различных национальных культур. В каждой из них отразилось своеобразное этническое мировидение. 
В этом отношении особый интерес представляет культурная картина мира современного арабского этноса. Известно, что полностью узнать арабский мир удается далеко не каждому; особенно же это касается арабской культуры, которая своеобразно формировалась под влиянием разных исторических факторов, успешно сохраняя традиции прошлого, а теперь уверенно идя в будущее. Как и любая другая, арабская культура имеет свои особенности, обусловленные спецификой ее исторического развития

Отличительной чертой арабско-мусульманской культуры является то, что ее фундаментом стал Коран и философия, которая получила в рамках этой культуры всестороннее развитие, причем раньше, чем в Западной Европе. Ислам стал одной из мировых религий и тем самым дал возможность создать единую общность народов и культуры на большой территории.

Другой типичный маркер арабской культуры - единство светской и религиозной составляющих, что объясняется неординарным истолкованием связи человека с Богом: «основной принцип в исламе - внеисторическая встреча человека с Богом и преподнесение ему своей судьбы» [10, с. 690].

Таким образом, своеобразие арабской культуры объясняется ее тесной связью с исламом, который можно определить как целостную философско-культурную систему.

Известно, что история русско-арабские связей уходит своими корнями в глубь истории, в частности в XI-XII веках оформились серьезные векторы ближневосточного курса Древней Руси, когда сложились торговые связи русских купцов с арабами. Заимствование арабизмов было опосредовано, как правило, тюркским влиянием; именно так в русский словарь попали арабизмы адмирал, алгоритм, баклажан, кофе. халат, халва, цифра и многие другие арабские слова.

В настоящее время арабский язык также один из достаточно активных восточных языков-доноров, в том числе и для русского языка. Среди причин усиления восточного влияния выделяются, прежде всего, социальнополитические конфликты на Ближнем Востоке, широко освещаемые современными СМИ; продвижение ислама в мире также обусловливает более широкое функционирование арабизмов в русской речи.

Среди арабских инолексем представлены хронологически разнотипные лексические единицы: давние заимствования, относительно новые, вошедшие в русский язык в советский и постсоветский периоды, и неологизмы; см., например: мазар «надгробное сооружение, почитаемое как святое», ураза «пост у мусульман», хадис «предание о пророке Мухаммеде», мумие «биологически активное вещество в виде смолы, распространенное к расщелинах скал», сель «грязекаменный поток в горах», джихад «война мусульман в защиту своей веры», хамас «исламское движение сопротивления», моджахед «участник религиозно-социальных движений на Ближнем Востоке», сафари «заповедник (обычно в Африке), где разрешена охота на диких зверей», рамадан «священный месяи nоста» и др. Несмотря на лингвистический интерес к арабским словам, в отечественной лексикологии они остаются недостаточно изученным пластом в словарном составе современного русского языка: как правило, научное внимание уделяется сферам функционирования рассматриваемых инолексем в русской языковой картине мира. Контрастивно-семантический анализ дает возможность установить лингвокультурную историю арабских слов, освоенных русским языком.

Одной из самых многочисленных групп арабизмов в русском языке является тематическая группа «Религия. Верования». Рассмотрим с указанной точки зрения наиболее известные слова данной группы.

\section{рус. Джихад / араб. الجهاد}

\begin{tabular}{l|l|} 
«Священная война; война, веду- & $\begin{array}{l}\text { «В исламе: внутреннее самоусо- } \\
\text { щершенствование на пути к }\end{array}$ \\
щаяся мусульманами в защиту & $\begin{array}{l}\text { к Аллаху как одна из главных } \\
\text { Серы, против иноверцев» } \\
\text { обя, с.107] }\end{array}$ \\
\hline I.А:Данностей мусульманина»
\end{tabular}

Модификация архисемы, мена дифференциальных и кннотативных сем

Как видно из схемы компонентного анализа, для носителей русского языка основным значением является понятие военного джихада В связи со сказанным данная лексема стала ассоциироваться с теми или иными проявлениями экстремизма и беззакония, что обусловило ее негативную коннотацию, поддерживаемую и смысловой корреляцией слова джихад с семантически близким именем существительным газават.

Однако верно ли это распространенное понимание джихада как «войны против неверных», которым его наделяют, специально или по незнанию средства массовой информации? 
«Джихадом в исламе является борьба со своими духовными или социальными пороками ... » [5], то есть джихадом можно назвать любую борьбу со злом и несправедливостью, она не обязательно должна быть направлена вовне и вестись с оружием в руках.

Современные СМИ демонстрируют семантическую генерализацию слова джихад. Данная лексема начинает функционировать в обобщенном значении «борьба, протест», утрачивая семантические компоненты религиозного характера; см.: «Дня не проходит, чтобы тот или иной мастер культуры не объявил в прямом эфире ... вендетту или джихад тому или иному критику» [Известия, 2002.12.27].

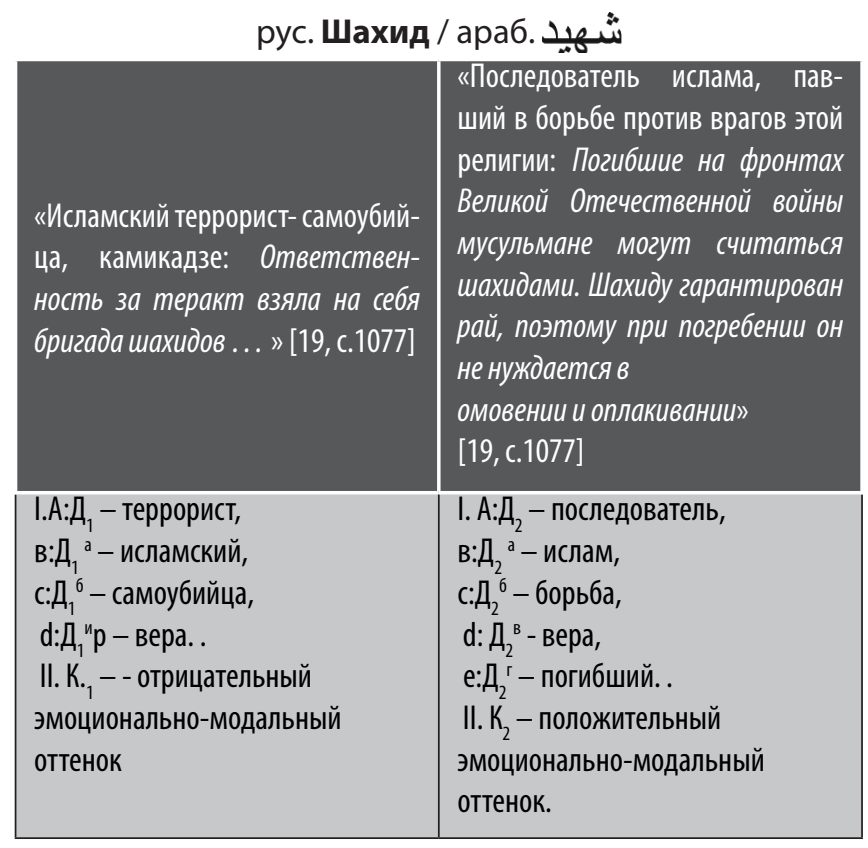

Мена дифференциальных и коннотативных сем

В арабской лингвокультуре шахид - человек, который принял тяжелую смерть от лица врагов, защищая свой дом, семью, родину, веру; при этом шахид - это не только воин, погибший в сражении, но и человек, имевший чистые помыслы и умерший в мучениях. Как и в христианской религии, в исламе высоко почитаются мученики, погибшие за религиозные идеалы [21]. Однако в российской этнокультуре содержание понятия шахид значительно отличается: шахид ассоциируется с террористами; в данном понятии стерты семы благородства и отваги - семантика этого слова включает в себя отрицательный эмоционально-модальный оттенок.

Таким образом, лингвокультурная история арабских лексем указанной сферы функционирования отмечена понятийно-коннотатиными осложнениями их этимологических значений, мотивированными не- равнозначным отношением носителей контактирующих языков к референту семантической структуры слова. В свою очередь данный социальный факт создает неоднозначный прагматический фон инолексемы..

\section{Ср. также:}

рус. моджахед: «... но в том-то и дело, что для них важно ... свидетельство того, что моджахеды способны на все и даже огромная Россия не может им nомешать» [19, с.604] - араб. محاهد : «Что за бред, удивятся мусульмане разумные, для которых ...моджахед - борец с пороками на пути к Всевышнему «[14].

Рассмотренные лингвокультурные изменения заимствованных арабских слов слова характеризуют лексемы, функционирующие и в других жизненных сферах российского социума.

Хиджаб - «головной убор мусульманских женщин, прикрывающий голову и плечи» [20].

В современном мире хиджабом допустимо именовать любую женскую одежду, которая демонстрирует принадлежность женщины к мусульманской вере. Это может быть как платок или паранджа, так и длинный плащ. Существует множество точек зрения шариатских ученых относительно того, что следует считать хиджабом, а что нет, однако в любом случае данная реалия и соответственно обозначающая ее арабская лексическая единица носят характер мелиоративов: ... Коран подчеркивает, что хиджаб является достоинством женщины [14].

В русской языковой картине мира арабизм хиджаб связан с неким отрицательным образом, противоречит привычным ценностным установкам, в связи с чем номинация имеет явно выраженный неодобрительный, порою пренебрежительный коннотативный ореол: В июле сотрудники охраны МГИМО отказались впускать абитуриентку, одетую в хиджаб, сославшись на внутреннее распоряжение, согласно которому учащимся не рекомендовано ношение мусульманских головных уборов [14]; Эти случаи включают ... оскорбление женщин, которые носят хиджаб [14]. Будучи в своем большинстве экзотизмами, арабизмы занимают периферию лексической системы русского языка до тех пор, пока не возникают экстралингвистические условия для их актуализации. Как указывает Е.В. Маринова, данное обстоятельство обусловливает расширение семантики слова за счет утраты ее локального компонента [ 11, с.329].

Широко известно в русском языке арабское слово кайф, обозначающее состояние, наступающее вследствие приятного безделья, расслабления. 
كус. Кайф/ араб. كايف

\begin{tabular}{|c|c|}
\hline $\begin{array}{l}\text { 1.Алкогольное или наркотическое } \\
\text { опьянение: о написании книги } \\
\text { парень давно забыл, вся жизнь } \\
\text { его теперь превратилась в чепь } \\
\text { одинаковых событий: поиск денег, } \\
\text { укол, кайф... } \\
\text { 2.Удовольствие: Бизнесменов, с с } \\
\text { кем дела вел, жалеть начал. 0б- } \\
\text { вожу их вокруг пальца, а прежнего } \\
\text { кайфа нет [19, с.436]. }\end{array}$ & $\begin{array}{l}\text { Приятные эмоции и ощущения в в } \\
\text { целом [6]: }\end{array}$ \\
\hline 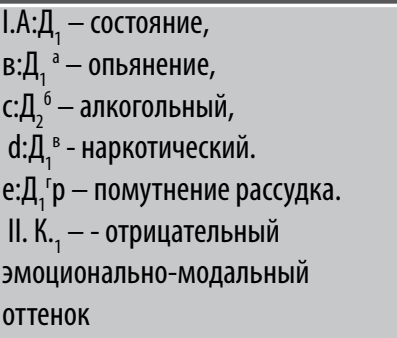 & 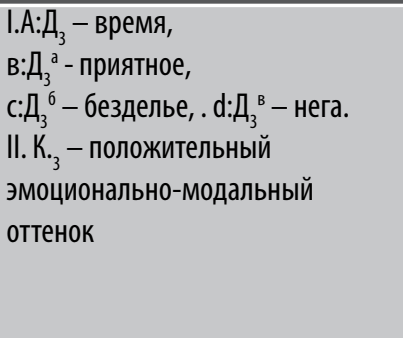 \\
\hline $\begin{array}{l}\text { І.А:Д - состояние, } \\
\text { е:Д'Гр - удовольствие } \\
\text { II. К.2-- положительный } \\
\text { эмоционально-модальный } \\
\text { оттенок }\end{array}$ & \\
\hline
\end{tabular}

Расширение значения, редукция

дифференциальных сем и мена коннотативных сем

Арабское слово «кайф» официально «зафиксировано в 1821 году». О.И. Сенковский, вспоминая путешествие в Египет, писал: «Путешественники, бывшие на Востоке, знают, сколь многосложное значение имеет выражение кейф. Отогнав прочь все заботы и помышления, развалившись небрежно, пить кофе и курить табак называется делать кейфр » [6]

В русской лингвокультуре слово кайф функционирует в субстандарте, также означая состояние максимального удовольствия, однако последнее обычно «не связано с вкушением кофе и щербета, как в арабской культуре; по мнению российской «золотой молодежи» и примкнувшим к ним последователей, а также некоторых деятелей мира искусства, кайф чаще наступает вследствие расслабления после употребления... определенных доз крепких напитков» [6].

Для современного состояния русского языка характерна такая интересная особенность, как достаточно активное функционирование в нем иноязычных вкраплений. Одно из самых последних заимствований подобного типа - междометная лексема иншалла, восходящая к устойчивому арабскому выражению ин шаа Алла. В арабских странах оно функционирует как эквивалент русским этикетным междометиям дай Бог, как Бог даст, с Божьей помощью, однако характер данного функционирования также не идентичен.
Носители арабского языковой культуры «непременно добавляют «иншалла», когда говорят о том, что намерены сделать в ближайшем или отдаленном будущем»; похожее руководство есть и у христиан в новозаветном Послании Иакова ..., где осуждаются люди, которые слишком самоуверенно говорят о своих планах, забывая, что они ничтожны и на все воля Божья» [22]. Несмотря на это, в современной русской лингвокультуре рассматриваемая этикетная формула такой речевой актуальностью не отличается.

Таким образом, вокабуляр языка, непосредственно связанный с объективным миром, есть тот механизм, единицы которого отражают иные в сравнении с транслирующим языком ценностные установки, связанные в свою очередь с индивидуальными свойствами той или иной национальной культуры и ментальности. Как считает И.А. Стернин, «В значительной мере ценности определяются идеологией, общественными институтами, верованиями и потребностями, причем совершение поступков, противоречащих ценностям, осуждается общественным мнением» [16, с. 109].

Разные векторы прагматической динамики лексических единиц свидетельствуют об изменении восприятия номинируемых объектов познания, новом видении последних принимающим языковым коллективом. В связи с этим этимологическое значение инолексем трансформируется; контрастивно-семантический анализ входящих в русскую языковую систему арабизмов констатирует, что при сохранении референтного значения заимствования сигнификативно-прагматическая часть его семантики модифицируется в зависимости от присущего участникам коммуникации концептуального взгляда на мир: разумеется, адепт немусульманской конфессии в отличие от сторонника противоположной точки зрения отрицательно окрашивает лексическую единицу, что способствует пейоративизации значения словарного этимона. Все сказанное позволяет констатировать следующие изменения в лингвокультурной истории арабских слов, проникающих в русскую концептуальную сферу: мена дифференциальных и коннотативных сем, редукция дифференциальных микрокомпонентов, появление потенциальных сем, расширение или сужение значения слова, то есть актуальными представляются трансформации семантического объема входящих лексем.

\section{Зак^ючение}

Таким образом, можно констатировать заметную актуализацию лексем арабского происхождения в современном русском языке, обусловленную интересом современного общества, в том числе российского, к культуре Востока, что репрезентирует прагматическая динамика инолексем. Конкретные примеры показывают, что в данном процессе особенно значимы компоненты, 
связанные с импликационалом семантики слова. Требуя знания дополнительных культурных ассоциаций, слова подобного типа, испытавшие указанную прагмадинами- ку, выступают как свидетельство изменения их восприятия носителями иной этно- и соответственно лингвокультуры.

\section{ЛИТЕРАТУРА}

1. Агеева А.В. Типология иноязычных вкраплений в русских текстах// Вестник Московского университета. Серия 22: Теория перевода. М.: Изд-во МГу, 2014 №1. C. 153-162

2. Арабская культура - информация на портале... [Электронный ресурс]. URL: http://w.histrf.ru > Периоды > ... /show / arabskaia kul ... (дата обращения: 01.09.2020).

3. Бергельсон М.Б. Кросскультурный анализ нарративной традиции северных табасков. Проблема грамматики и типологии, М: Гнозис, 2010. С. 37-59.

4. Голованивская М.К. Ментальность в зеркале языка. Некоторые базовые мировоззренческие концепты французов и русских. М. : Языки славянской культуры, 2009.376 с.

5. Джихад - Википедия [Электронный ресурc]. URL:http:// ru.wikipedia.org/wiki/Джихад] (дата обращения: 12.09.2020).

6. Кайф - Википедия [Электронный ресурc]. URL:http://u.wikipedia.org) Кайф (дата обращения: 01.09.2020).

7. Каналаш 0.П. Яыковая и национальная картины мира как компонент лингвистического исследования// Lingua mobilis №1 (27), 2011. C. 60 - 64.

8. Колесов В.В. Язык и ментальность. СПб.: Петербургское востоковедение, 2004. 247 с.

9. Кросскультурный - Викисловарь [Электронный ресурс]. URL: http:// /ru.wiktionary.org'wiki/кросс-культурный] (дата 0бращения: 01.09.2020).

10. Макаева Г.З. Влияние эстетики ислама на арабо-мусульманскую культуру // Вестник Башкирского университета. 2008. №297. С. 690-692.

11. Маринова Е.В. Иноязычные слова в русской речи конца XX - начала XXI в.: проблемы освоения и функционирования. М.: Элпис, 2008. 495с

12. Маслова В.А. Лингвокультурология. М.: Издательский центр «Академия», 2001.208 с.

13. Моджахед - Википедия [Электронный ресурc]. URL: http: // ru.wikipedia.org`Моджахед (дата обращения: 01.09.2020).

14. Национальный корпус русского языка [Электронный ресурс]. URL: http://www.ruscorpora.ru/new// (дата обращения: 19.08.2020).

15. Норлусенян В.С. Иноязычные вкрапления: современное состояние проблемы// Вестник Новгородского государственного университета им. Ярослава Мудрого. 2010. №57. С.63-66.

16. Стернин И.А. Коммуникативное поведение в структуре национальной культуры // Этнокультурная специфика языкового сознания. М.: Проект, 2000. C. $97-113$

17. Стернин И.А. Контрастивная лингвистика // Научная школа профессора 3.Д. Поповой. Коллективная монография Воронеж: «Истоки», 2018. С. 66 - 71.

18. Телия В.Н. Русская фразеология: Семантический, прагматический и лингвокультурологический аспекты». М.: Языки русской культуры, 1966. 288с

19. Толковый словарь русского языка начала XXI века. Актуальная лексика. М.: Эксмо, 2006. 1136 с.

20. Хиджаб - Викисловарь [Электронный ресурс]. URL: http://ru.wiktionaru.org`wikiхииджаб (дата обращения: 01.09.2020).

21. Шахид - это мученик за веру или... [Электронный ресурс]. URL: https://www.syl.ru/article/331567/shahid---eto-muchenik-za-veru-ili-terrorist-smertnik] (дата обращения: 01.09. 2020).

22. Что значит «иншалла »? Перевод. Как правильно говорить? [Электронный ресурс]. URL: http://anews.com`p/118607769-chto-znachit-inshalla.. . kak. . . (дата обращения: 01.09. 2020).

(с Сенько Елена Викторовна (senkoelena@yandex.ru), Гариева Зарема Давидовна (kazieva96@bk.ru).

Журнал «Современная наука: актуальные проблемы теории и практики» 